\title{
Knowledge Networks around the Strategic Alliances of Micro Coffee Producers
}

\author{
Enrique Vázquez-Fernández ${ }^{1}$, Javier Carreón Guillén ${ }^{2}$, Arturo Sánchez Sánchez ${ }^{3}$ \\ ${ }^{1}$ Autonomus University of Tlaxcala. Tlaxcala, Tlax. \\ ${ }^{2}$ National Autonomous University of Mexico, Coyoacán, Mexico City \\ ${ }^{3}$ Autonomus University of Tlaxcala, Tlaxcala, Tlax
}

\begin{abstract}
The organizational process that goes from the knowledge networks to the strategic alliances supposes a management, production and transfer of information that the literature differentiates according to the degree of empathy, commitment, entrepreneurship, innovation and satisfaction of leaders and followers. In this sense, the objective of this study was to study the phenomenon in coffee growers in central Mexico. From a structural model $\left\lceil X^{2}=321.23(34 \mathrm{gl}) \quad p=0.009 ; \mathrm{GFI}=0.990 ; \mathrm{CFI}=\right.$ $0.975 ;$ RMSEA $=0.008 \mathrm{~J}$, after establishing the reliability and validity of an instrument, it was found that innovation determines satisfaction (0.51), although the type of study, sample selection and analysis limit the findings to the specific context of the investigation. Lines concerning the extension of work to different contexts and samples are noticed.
\end{abstract}

Keywords-Governance, networks, alliances, entrepreneurship, innovation, satisfaction.

\section{INTRODUCTION}

The objective of this paper is to establish the challenges and opportunities of micro, small and medium enterprises dedicated to the management, production, administration and marketing of coffee in Xilitla, a town located in San Luis Potosi, central Mexico, facing the protectionist policies of the United States. government of Donald Trump .

Based on an economic-administrative approach focused on the production of knowledge oriented towards entrepreneurship and innovation, the present work will show that: 1) the economic, political and social crisis of developed countries negatively and positively affects emerging economies, considering the challenges of product quality and the competitiveness of services, but at the same time, encourage entrepreneurship and innovation of micro, small and medium enterprises; 2) in the case of entrepreneurship and innovation, both explain the economic relationship between the United States and Mexico, mainly the relationship established by micro, small and medium enterprises dedicated to the management, production, administration and marketing of coffee in Xilitla and that, migratory flows have exacerbated such codependency; 3) specifically, coffee marketing networks have generated capital - intellectual, social and administrative - from which local and regional development is explained.

However, the understanding-interpretation and measurement of the phenomenon of intellectual, social and administrative capital around entrepreneurship and innovation of coffee micro-enterprises in Xilitla has not been unveiled or linked to international markets as a factor of local and regional development. regional, but with international quality standards such as the consumer market in Germany, the main point of sale and marketing of coffee produced in Latin America and in the case of Mexico the town of Xilitla, even though the US market has historically been the client Mainly, the emergence of protectionism in the administration of President Trump has forced to diversify the client portfolio.

Therefore, the study of the challenges of the US market and the opportunities of the German market are essential in the management, production, administration and commercialization of micro, small and medium coffee companies in Xilitla.

However, the US market challenges and opportunities in the German market are confined to innovation and that, on a scale from 1 to 10 US market it ranks in third place and the German market in sixth place.

Economist Intelligence Unit (EIU) in its report for 2014 warns that there is an imbalance in the economic exchange between the EU and Germany in favor of this last Central European economy in the last 30 years .

Such commercial relationship is due to an ancestral bond of 15.7\% between Americans and Germans that exceeds the relationship between Mexico and the United States, which is $10.6 \%$. 
In other words, both economies, being linked as ancestral networks and networks of innovation, reflect the differences between both economic and organizational cultures. This is because both countries have developed from production and retail. In the case of the EU, it occupies the second place and Germany the third .

In other words, entrepreneurship and innovation in both developed economies, American and German, are focused on retail and strengthened through ancestral networks, but with a clear difference in favor of Alemania.

Even electronic commerce, buying and selling online, is focused on mobile telephony in Germany exceeded $100 \%$ and in the EU 58\%, with the German market the second most dynamic and the American the last place .

Indeed, the commercial asymmetries between Germany and the EU are not only explained by their social capital or ancestral networks, not only by their retail culture, but also by their population that in Germany synchronizes technological advances and electronic devices with their lifestyle and In the US, a deceleration in consumption is evident.

However, the German population occupies the last places in terms of the birth rate -8 births per thousand inhabitantswhile in the US there are 14 births per thousand inhabitants. Although in Germany the number of births is less than the number of deaths, the economy 4.0 or digital economy is booming with the payment of online services .

That is to say that, despite the population slowdown in Germany, retail trade is essentially online and this digital retail culture is linked to the US market by its ancestral networks and its commercial exchange.

In this sense, the 81.8 million inhabitants, the German economy and its digital culture (69.5 million Internet users) and retail (37 million consumers) represent $19 \%$ of the total commercial volume of Europe, $18 \%$ in favor in the exchange with the US, $19 \%$ of central Europe.

Both US and German markets are not only linked, but also key in terms of challenges and opportunities for Mexico's products and services in general and the sale of coffee in Xilitla in particular, since both developed economies occupy the first and second place of import of products derived from coffee.

\section{Conceptual theoretical framework}

The theoretical and conceptual frameworks that explain entrepreneurial and organizational innovation and digital menudista warn determinants of growth that would be: 1) environmental, 2) sociological, 3) personal and 4) organizational.

The present work will focus on human capital, its entrepreneurship and innovation that are considered preponderant factors in developed economies.

\section{Theory of strategic alliances}

The demands of the market to envelope the resources of the organization induce the latter to establish strategic cooperation alliances in order to increase the capabilities of MSMEs with the support of transnationals, or develop competitive strategies through technology transfer and the implementation of the quality of processes and products. In this way, MSMEs survive the selection process and add to the multiplier effect of investments, transfers and procedures.

In this way, in an organizational and political sense, the strategic alliances between micro-enterprises are gestated from the confluence of objectives, tasks and goals (see Table 1).

\section{Table.1: Taxonomy of strategic alliances}

\begin{tabular}{|c|cc|}
\hline \multicolumn{1}{|c|}{ Goals } & Chores & Goals \\
\hline Customer satisfaction & $\begin{array}{c}\text { Distribution agreements, alignment } \\
\text { proposal, trademark cooperation }\end{array}$ & $\begin{array}{c}\text { Market expansion, presence and local-global capacity, contact } \\
\text { lines and points of sale, mutual reference, relevance of the } \\
\text { brand }\end{array}$ \\
$\begin{array}{c}\text { Product / service } \\
\text { development } \\
\text { Creation of } \\
\text { competitive } \\
\text { advantages }\end{array}$ & $\begin{array}{c}\text { Joint project, technology license } \\
\text { of staff, supply risks }\end{array}$ & Use of external technology and capacity \\
& &
\end{tabular}

Source: self made.

\section{Theory of knowledge networks}

From the advent of information and communication technologies (ICTs), competitiveness and the establishment of a climate relations emerges the systematization of internal and external resources in order to establish an organizational change oriented to the development of processes and products, as well as to the implementation of quality criteria and protocols. In the case 
of the adoption of technology, it involves a transfer of skills and knowledge that can be established between institutes and MSMEs with the assistance of the local or federal government, the main promoter and sponsor of investment fairs or entrepreneurial development, as well as training, practice and employment (see Table 2) .

Table.2: Taxonomy of Knowledge Networks

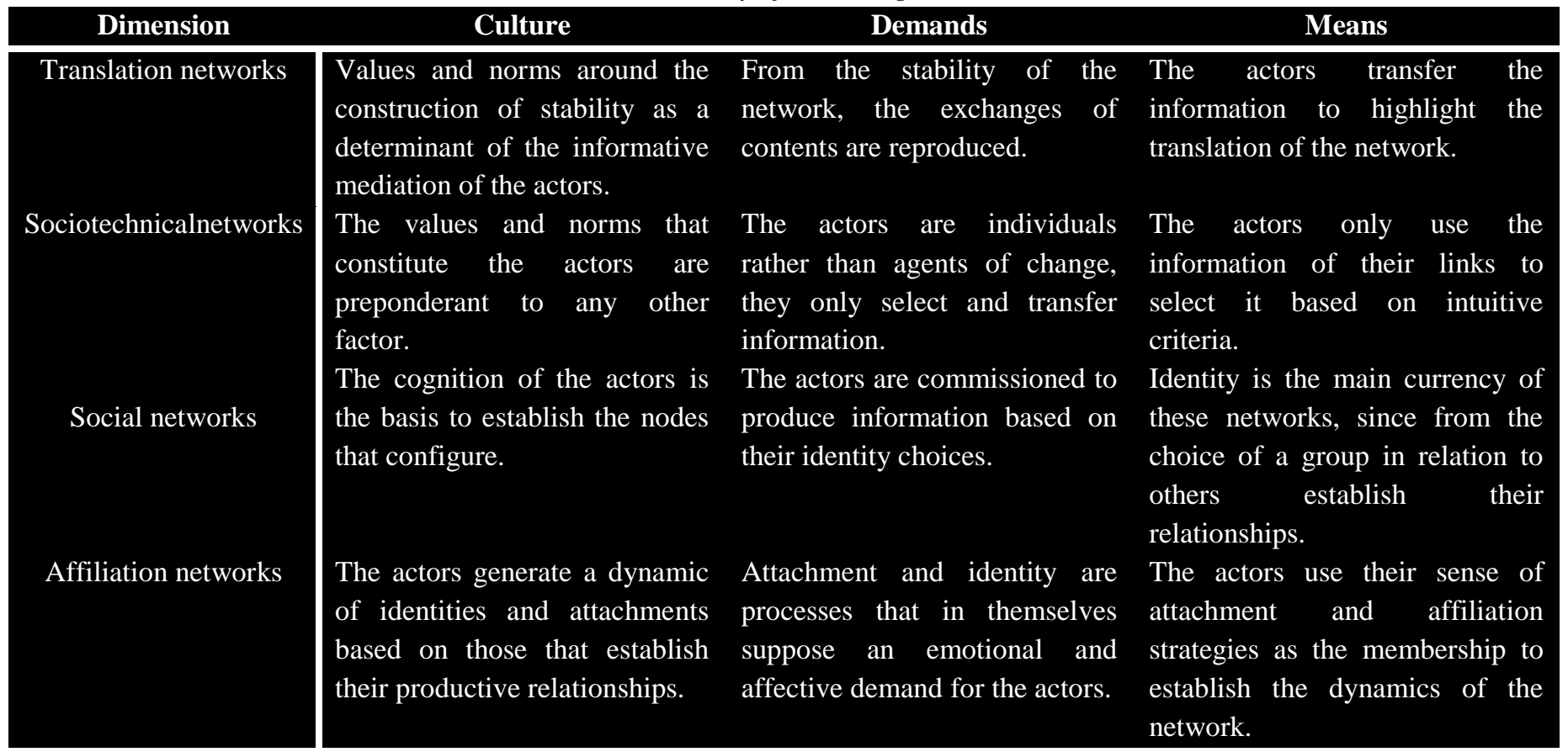

Source: self made

If the theory of human capital warns that the differences between organizations are gestated from their intellectual, technological and social capital, then the theory of entrepreneurship and innovation will suggest that the asymmetries between organizations are focused on the production of knowledge indicated as market opportunities. In the framework of ICTs, the organizations established strategic alliances and knowledge networks with the aim of enhancing their human, intellectual and innovative capital. The prevalence of the climate of relations and the climate of innovation with respect to the climate of tasks and the climate of support led to the creation of knowledge and added values to the products and organizational processes, increasing their quality, diversity and complexity. In this sense, the diffusion of innovations not only determines consumption, but also the establishment of sectors such as: innovators, followers, early, late and laggards (see Table 3).

Table.3: Academic networks taxonomy

\begin{tabular}{|c|c|c|c|}
\hline Dimension & Social representations & Social identity & Human motivation \\
\hline $\begin{array}{c}\text { Translation } \\
\text { networks }\end{array}$ & $\begin{array}{l}\text { The information surrounding the } \\
\text { networks is processed in order to } \\
\text { establish a synthesis between the } \\
\text { human and the technological. }\end{array}$ & $\begin{array}{l}\text { The processed information of } \\
\text { the environment is determinant } \\
\text { of the choice of a technology } \\
\text { and the exchange with another } \\
\text { network. }\end{array}$ & $\begin{array}{l}\text { The needs of achievement are } \\
\text { determinants of the association } \\
\text { between technologies and humans. }\end{array}$ \\
\hline $\begin{array}{l}\text { Socio } \\
\text { technical } \\
\text { networks }\end{array}$ & $\begin{array}{l}\text { The information considered as an } \\
\text { instrument of persuasion establishes } \\
\text { a specific knowledge network. }\end{array}$ & $\begin{array}{l}\text { An increase in the demand for } \\
\text { information generates subsidies } \\
\text { in the network. }\end{array}$ & $\begin{array}{l}\text { The subsidy is the resource used in the } \\
\text { face of an increase in information } \\
\text { demands and selection in the case of a } \\
\text { decrease in demand. }\end{array}$ \\
\hline Social & The impact of the surrounding & The information that favors & $y$, as an intuitive selection tool, \\
\hline
\end{tabular}




\begin{tabular}{|c|c|c|c|}
\hline Dimension & Social representations & Social identity & Human motivation \\
\hline networks & $\begin{array}{l}\text { information on the prestige of } \\
\text { the actors implies a social } \\
\text { representation of the network and } \\
\text { its environment. }\end{array}$ & $\begin{array}{l}\text { differences between the actors } \\
\text { with respect to the network is } \\
\text { widely valued. }\end{array}$ & is the main currency of the network. \\
\hline $\begin{array}{l}\text { Affiliation } \\
\text { networks }\end{array}$ & $\begin{array}{l}\text { The information is represented as } \\
\text { an indicator of a specific network. }\end{array}$ & $\begin{array}{l}\text { The identity is assumed as a } \\
\text { demand of the environment that } \\
\text { determines the configuration of } \\
\text { a network. }\end{array}$ & $\begin{array}{l}\text { The sense of belonging and } \\
\text { attachment are determinants of the } \\
\text { network, its processes and products. }\end{array}$ \\
\hline
\end{tabular}

Source: self made

In the case of entrepreneurship and innovation required for the US and German markets, retailing in digital protocols involves intellectual, digital and social networks such as the commercial relationship between the EU and Germany, but as an asymmetry in favor of Germany, then the theory of entrepreneurship and innovation, in the case of Mexico, will explain the creation and emergence of scenarios in which emerging organizations will access international markets through these same digital and social knowledge networks.

\section{Theory of human capital}

From the economic theories of rational choice, the theory of human capital was established as an explanatory conceptual framework of organizational creativity, spearhead of internal and local development.

In this sense, the concepts of intellectual, technological and social capital reflected in the retail marketing of coffee in digital protocols of the US and German markets are fundamental to explain the challenges and opportunities of both international markets in local and regional MSMEs .

\section{Intellectual capital}

It alludes to capabilities; skills and knowledge related to management, production and commercialization (Pariente, 2006). In the case of the purchase and sale of coffee, the intellectual capital would be indicated by the opportunities that MSMEs generate in the face of the challenges of the digital retail market in Germany and the retail market in the US. It deals with strategies and management styles inMSMEs in face of the challenges and opportunities of both international markets.

\section{Technological capital}

It refers to the commercialization devices and networks of products and services specialized in buying and selling retail (Caballo, $R$ eyes and Solis, 2006). In the case of coffee, these are portals of MSMEsthat will encourage the purchase and sale of coffee between Mexico and the EUGermany.

\section{Social capital}

It refers to the knowledge and marketing networks of products and services in developed economies and emerging countries (Domínguez and Fuentes, 2006). It deals with knowledge about the distribution of objectives, responsibilities, tasks and goals related to the purchase and sale of coffee in electronic portals and digital money transfer protocols.

\section{STUDIES OF KNOWLEDGE NETWORKS AND STRATEGIC ALLIANCES}

Organizational studies have focused their interest on the factors of empathy, commitment, cooperation, entrepreneurship, skills, innovation and satisfaction as structuring the process of networking with orfoundation and strategic alliances.

Ramos, (2013) established four factors related to the growth of MSMEs : production capacity (alpha of 0.912 , knowledge of the market (alpha of 0.825), product differentiation (alpha of 0.742) and logistics)alpha of 0.864). However, MSMEs would have their main multiplying factor in the dissemination of their products and services in digital protocols such as Facebook (Martínez, 2012 ). In another study, 60\% of MSMEs have not established an organizational management, production and quality control (Contreras, 2012), but customer perception that determines the purchase of products and the requisitioning of services MSMEs ( Castiglioni, Castro and Galán, 2015 )

\subsection{Foundation of the problem}

The study of entrepreneurship and innovation in micro, small and medium enterprises of online retail of coffee in Xilitla with respect to the challenges and opportunities of the US and German market, involves the study of their capital networks in terms of their capabilities intellectual, technological and social.

Therefore, the qualitative approach of the meanings around the quality of the processes and the competitiveness of the products derived from the coffee in the international mark, but especially in the American and German will show the strategies of entrepreneurship and innovation necessary to 
transfer them to the micro, small and medium enterprises of Xilitla.

In this way, the transfer of technology will be an essential management tool to strengthen the dynamics of local production and marketing with respect to the global market, mainly in the consumption of coffee by potential US and German customers.

\section{Justification}

Given that MSMEs explain $90 \%$ of global employment, $95 \%$ of national employment and $97 \%$ of local employment, it is necessary to unravel the strategies of electronic and digital entrepreneurship and innovation necessary for local and regional development with respect to international coffee market. It is an organizational process in which the retail trade of coffee explains a high percentage of the digital economy around its consumption much more frequent than water or beer in the US and Germany.

In the same sense, the policies of business and industrial development of coffee exporting countries with respect to importing countries, seem to show that the differences lie in management strategies, management, production and marketing, but these dimensions are not entirely present in micro and small companies, as well as very rare in mediumsized companies.

In this way, a strategic alliance between the mipymes of the coffee sector in Mexico, mainly in San Luis Potosí and essentially in Xilitla, seems to be a logical response to the challenge of the US and German markets.

\section{Approach}

In virtue of the fact that entrepreneurship is the result of association and economic exchange between developed and emerging countries, it consists of an exchange of production and reproduction of knowledge that would be activated by strategic alliances, the competition of capital, the skills of force labor and the evaluation of resources.

In emerging economies, entrepreneurship is the preponderant factor that will determine the learning, performance and results of companies through the links established between the networks of entrepreneurship.

Grosos modo, the entrepreneurial process starts from surrounding information about a product or service that is presumed to be indispensable for a niche market, continues with the socialization of that need or expectation, very soon, potential customers will develop an adaptive response or creative and from these two routes on the first path will experience experiences of satisfaction or dissatisfaction more likely in the trajectory of creative response.

However, this proposal lacks an explanation regarding the differences between micro, small and medium enterprises with respect to entrepreneurship and innovation around the retail marketing of coffee and its dissemination in Internet networks.

\section{Object of study}

The present work focuses its interest on entrepreneurship and innovation as factors of local development strategies from the retail and digital commerce of coffee, its derivative products and related services.

However, the generality of the process of entrepreneurship and innovation supposes its delimitation to the MSME organizations that, for the objectives of the present work will be specified to the management, production and commercialization in tune with the needs and expectations of the American and German client.

\section{Object of investigation}

The present study will observe the entrepreneurship and innovation process of MSMEs, considering the potential client. In this sense, the project is part of the creative and digital economy, since it studies essentially observable processes and phenomena in the interaction between consumer and seller online and retail.

However, the study of the coffee growing MSMEs Xilitla is not reduced only to the present or seed capital and its emergence in the international arena, it will be crucial to observe and compare their developmental stages within the US and German retail and digital commerce.

It is an evolutionary process in which crises encourage the entrepreneurial and innovative development of organizations, observable in changes, adaptation and the adoption of revolutions. It is an evolutionary process in which organizations are circumscribed in order to thrive in developed economies.

\section{Formulation}

What will be the differences between the organizations developed with respect to emerging SMEs in terms of retail marketing of coffee through digital protocols?

What are the meanings organizations in developed economies have generated about retail marketing and electronic distribution of coffee products and derivatives?

How can transfer the meanings around entrepreneurship and innovation in MSMEs in Mexico, mainly in Xilitla meeting their particularities and localism?

What are the meanings of strategic alliances, knowledge networks and innovation climate in micro-entrepreneurs of a coffee growing area in central Mexico?

\section{Hypothesis}

The differences between organizations of the first world and the MSMEs of emerging countries will be based on the 
strategies of entrepreneurship and innovation exacerbated in developed economies with respect to emerging markets .

Because coffee marketing organizations are focused on retailing through digital protocols, then it will be possible to observe that coffee acquires a value in itself, coupled with the accessibility of Internet sales, its value will be higher.

In this regard, the marketing strategies adopted in organizations competing in developed economies, allow a transfer of focusing on entrepreneurship and innovation in order to transform the local and regional market knowledge Xilitla coffee growing MSMEs.

\section{Sample}

A non-probabilistic sampling was carried out with an intentional selection of four informant entrepreneurs, considering their experience in strategic alliances, knowledge networks and innovation climate. Anintentional selection of 10 local coffee growers was carried out for the study in its qualitative phase and a non-probabilistic selection of 130 regional coffee merchants, considering the size of their organization, the retail approach and their accessibility or penetration in digital networks ( see Table 2).

\section{METHOD}

\section{Design}

A non-experimental, cross-sectional, exploratory, qualitative and quantitative study was carried out.

Table 4. Sample descriptive

\begin{tabular}{|llll|lllll} 
Entrepreneur & Sex & Age & Scholarship & Status & Foundation & Alliances & Collaborations & Innovations \\
\hline Candidate & Female & 27 & Bachelor's degree & Single & 2014 & 1 & 1 & 0 \\
Micro & Female & 33 & Bachelor's degree & Single & 2010 & 2 & 3 & 0 \\
Little & Male & 41 & Bachelor's degree & Married & 2009 & 4 & 5 & 0 \\
Medium & Male & 52 & Bachelor's degree & Married & 2006 & 6 & 7 & 1
\end{tabular}

Source: Prepared with the study data

\section{Instrument}

An interview guide was prepared considering the categories of strategic alliances, knowledge networks and innovation climate. The questions were included: What is the starting year of your organization?What have been the objectives, tasks and goals of your organization in the last three years? What have been the strategic alliances of your organization in the last three years? How have the types of collaboration of your organization been in the last three years? What and how are processes and / or innovative products that your organization carried out in the last three years?

A scale of entrepreneurship and innovation was built in retail organizations with presence on the Internet and contacts in the US and Germany. It will include referents alluding to the dimensions of entrepreneurship and innovation such as: opportunism, utility, quality, strategy, transversality, flexibility and risk.

\section{Process}

The interviews were conducted at an entrepreneurship fair, with a guarantee of confidentiality and anonymity in writing, as well as a warning that the results of the study would not affect the economic status of the respondents. The information was processed in the qualitative data analysis package (QDA by its acronym in
English version 4.0). Arrays of analysis of discourses and networks of discursive extracts were elaborated with the purpose of interpreting the meanings of the answers to the questions.

\section{Analysis}

\section{Discursive}

The meanings of the answers to the questions were analyzed from the reflective indicators of the categories of strategic alliances, knowledge networks and climate of innovation in order to select the discursive extracts. Once a list of extracts was compiled, they were sorted according to their relationship with each of the categories related to habitusstyle of entrepreneurship, innovation and collaborationlearned, inherited, vertical or horizontal.

\section{Reliability}

The Crombachh alpha coefficient was estimated to show the internal consistency of the instrument in different contexts and samples.

\section{Validity}

Adequacy

The statistic Kay ser- Meyer- Olkin was weighted to establish the possible correlations between the indicators and the factor. A value close to 1 will show an adequate distribution, but a value lower than 0.6 suggests a reduction of the items on the scale. 


\section{Sphericity}

The Bartlett test was carried out to establish the ideal factorial solution for the validity analyzes. In the same way, a value close to zero or the unit shows a distribution according to validity.

\section{Exploratory factor analysis}

An analysis of principal axes with promax rotation was carried out, following the logic of values close to the unit as evidence of construct indicators and close to zero as evidence of indicators of other constructs.

\section{Contingency}

$\mathrm{N}$ tables chi squared correlations to demonstrate the dependence or independence between the variables and their interpretation of differences between independent samples elaboraro. A non-significant value is interpreted as an independent relationship between the variables.

\section{Correlation}

The Pearson correlation coefficient P was estimated to establish the possible associations between the variables to be measured in the instrument. Values close to one demonstrate a strong association and probable relationship of dependence. Values close to zero will be assumed as spurious.

\section{Regression}

The dependency relations were established between the variables related to entrepreneurship and the indicators linked to innovation as factors of local and regional development. Beta values close to the unit show dependency relations and close to zero show that there are other variables not included in the relationship.

\section{Structure}

\section{Adjustment}

The goodness of fit and the fit index were weighted to show that the relations between the variables stated in the state of theoretical knowledge are adjusted to the relations observed in the empirical study, values close to unity mean the acceptance of the null hypothesis of It corresponds nce between theory and empiri a.

\section{Residual}

It was estimated the adjustment coefficients to show the probability of measurement error and the acceptance of the null hypothesis of correspondence between the matrix of expected observations and the matrix of estimated weights.

\section{RESULTS}

The discourses related to knowledge networks and strategic alliances are involved in innovation and the habitus or instrumentation of organizational values around the management, production and sale of coffee, as well as in the insertion to the international market as an opportunity to introduce pesticide-free and organic products, friendly with the environment and occupational sustainability in terms of health, prevention of diseases and accidents.

Table 5 shows reliability values of the general scale (alpha of 0.771 ) and subscales (alphas of 0.755 to 0.791 ) sufficient to establish the internal consistency of each of them.

Table 5. Instrument descriptions

\begin{tabular}{|c|c|c|c|c|c|c|c|c|c|c|}
\hline Code & Item & $\mathbf{M}$ & FROM & TO & F2 & F3 & F4 & F5 & F6 & F7 \\
\hline EP1 & $\begin{array}{l}\text { Mistrust before the } \\
\text { elections }\end{array}$ & 3.21 & 1.01 & 0,712 & & & & & & 0.331 \\
\hline EP2 & Post-election negotiation & 3.82 & 1.02 & 0.732 & & & & & & 0.302 \\
\hline EP3 & $\begin{array}{l}\text { common agenda before } \\
\text { elections }\end{array}$ & 3.45 & 1,03 & 0.743 & & & & & & 0.431 \\
\hline CM1 & $\begin{array}{l}\text { Higher sales before } \\
\text { elections }\end{array}$ & 3.67 & 1.01 & 0.741 & & & & & 0.493 & \\
\hline $\mathrm{CM} 2$ & $\begin{array}{l}\text { Micro-financing before } \\
\text { elections }\end{array}$ & 3,04 & 1.00 & 0,742 & & & & & 0.312 & \\
\hline CM3 & Indebtedness after elections & 3,13 & 1.05 & 0.731 & & & & & 0.403 & \\
\hline $\mathrm{CP} 1$ & Support after elections & 3.82 & 1.08 & 0.754 & & & & 0.319 & & \\
\hline $\mathrm{CP} 2$ & Competition from elections & 3.05 & 1.08 & 0.721 & & & & 0.401 & & \\
\hline CP3 & Solidarity before elections & 3.46 & 1.00 & 0.772 & & & & 0.403 & & \\
\hline EM1 & Branches before elections & 3,14 & 1.02 & 0.783 & & & 0.493 & & & \\
\hline EM2 & $\begin{array}{l}\text { Developments after } \\
\text { elections }\end{array}$ & 3.67 & 1,03 & 0.792 & & & 0.301 & & & \\
\hline EM3 & Offers before elections & 3.94 & 1,04 & 0,742 & & & 0.493 & & & \\
\hline CD1 & Liquidity after elections & 3.05 & 1.02 & 0,715 & & 0.399 & & & & \\
\hline
\end{tabular}




\begin{tabular}{|c|c|c|c|c|c|c|c|c|c|c|c|}
\hline Code & Item & $\mathbf{M}$ & FROM & TO & F1 & F2 & F3 & F4 & F5 & F6 & F7 \\
\hline EP1 & $\begin{array}{l}\text { Mistrust before the } \\
\text { elections }\end{array}$ & 3.21 & 1.01 & 0,712 & & & & & & & 0.331 \\
\hline EP2 & Post-election negotiation & 3.82 & 1.02 & 0.732 & & & & & & & 0.302 \\
\hline $\mathrm{CD} 2$ & $\begin{array}{l}\text { Contrastaciones } \quad \text { before } \\
\text { elections }\end{array}$ & 3,12 & 1.05 & 0.725 & & & 0.413 & & & & \\
\hline CD3 & Expansion after elections & 3.05 & 1.08 & 0.721 & & & 0.403 & & & & \\
\hline IN 1 & $\begin{array}{l}\text { Change of rotation before } \\
\text { elections }\end{array}$ & 3.74 & 1,03 & 0.732 & & 0.384 & & & & & \\
\hline IN 2 & I nvesting after the election & 3.56 & 1.02 & 0.743 & & 0.302 & & & & & \\
\hline IN3 & A sociarse before elections & 3.15 & 1.01 & 0.725 & & 0.321 & & & & & \\
\hline ST1 & Bonanza before elections & 3.52 & 1.01 & 0.731 & 0,315 & & & & & & \\
\hline ST2 & after election losses & 3.94 & 1.01 & 0.725 & 0.382 & & & & & & \\
\hline ST3 & $\begin{array}{l}\text { Opportunities } \quad \text { before } \\
\text { elections }\end{array}$ & 3.05 & 1,11 & 0.731 & 0.324 & & & & & & \\
\hline
\end{tabular}

Extraction method: principal axes, rotation promax . Adaptation and sphericity $\left\lceil\mathrm{X}^{2}=324.15(234 \mathrm{gl}) \mathrm{p}=0.001 ; \mathrm{KMO}\right.$ 0,721 J $. \mathrm{M}=$ mean, $\mathrm{SD}=$ Standard Deviation, $\mathrm{A}=$ Alpha Crombach removing the value of the item. $\mathrm{F} 1=\mathrm{empathy}(\mathrm{alpha} 0.778$ and $27 \%$ of the total variance explained), F2 = Commitment (alpha 0.780 and $23 \%$ of the total variance explained), F3 $=\mathrm{Co}$ (alpha 0.791 and $20 \%$ of the total variance explained), F4 = Entrepreneurship (alpha 0.775 and $17 \%$ of the total variance explained), F5 = Capacity (alpha 0.781 and $13 \%$ of the total variance explained), F6 = Innovation (alpha 0.755 and $11 \%$ of the total variance explained $),$ F7 = Satisfaction ( 0.760 alpha and $9 \%$ of the total variance explained). All items are answered with one of five response options: 0 all likely, $1=$ very unlikely, $2=$ unlikely, $3=$ somewhat likely, $4=$ very likely.

Source: Elaborated with data from the study

Dependency relationships among the factors put forward in the state of the art and have been weighted case study. The innovation factor determined directly, positively and significantly satisfaction (0.51), but its effect is low, even relative to other interrelationships between factors is the highest.

Finally, the adjustment parameters and residual $\left\lceil\mathrm{X}^{2}=\right.$ $321.23(34 \mathrm{gl}) \mathrm{p}=0.009$; GFI $=0.990 ; \mathrm{CFI}=$ $0.975 ;$ RMSEA $=0,008 \mathrm{~J}$ sugieren acceptance of the null hypothesis concerning the adjustment of the theoretical relationships regarding the data.

\section{DISCUSSION}

The contribution of this work lies in the interpretation of the meanings of informants entrepreneurs regarding the categories of strategic alliances, networks of knowledge and innovation climate. Regarding the study of Villegas et al., (2016) who found that knowledge of the market determines the growth of MSMEs, in this study it was observed that the informants have entrepreneurship, innovation and collaboration related to coffee growing history the location. This finding contravenes the contribution of Sixto, Aguado and Ribeiro (2017) who showed that Internet is the broadcaster par excellence of MSMEs in its growth process. Although Marquez et al., (2017) warns that the organization is essential to define the objectives, tasks and goals of MSMEs, in this study it was shown that these by establishing alliances, networks and climates feed back of organizational experience peers with which they are associated. Even the results of this study contradict the finding Hoyos and Lasso (2017) to ensure that customer perception is the determining factor in the growth of MSMEs. In the present study rather it is noted that coffee is the history of the town and the creativity of informers which had an impact for the MSMEs not only maintained, but also followed an upward trajectory.

\section{CONCLUSION}

The limits of this study are: 1) the type of exploratory, transversal and qualitative research to find that coffee is the history of the locality and creativity affect entrepreneurship, innovation and collaboration of MSMEs;2) the interpretation of the meanings of partnership, knowledge and innovation to assume that these are the processes that guide the change of MSMEs, sidestepping their customs; 3) the differences with the state of knowledge regarding the management and administration of the three categories in comment. 
It is recommended that: a) carry out a quasi-experimental study to establish the incidence of factors that control could reveal the degree of entrepreneurship, innovation and collaboration; 2) establishing paths dependency relationships between variables in comment; 3 ) implement the effect of other variables such as micro-financing to observe changes in a period of time.

\section{ACKNOWLEDGMENTS}

The article is derived from the project "Governance of Knowledge Networks and estrat alliances égicas between micro and Institutions of Higher Education", funded by the National Autonomous University of Mexico, General Directorate of the Academic Staff, Program Support Project Research and Technological Innovation, register IN305516.

\section{REFERENCES}

[1] Berrou, JP and Combaunous, F. (2012). The staff networks of entrepreneurs in a casual African urban econo my. Does the strength of ties matter? Review of Social Economy , 1, 1-30

[2] Caballlo, A., Reyes, R. Solis, P. (2006). The competitive strategy adopted transnational company in the global market. Accounting and Management, $50,89-122$

[3] Carreon, J. (2016). Human Development: Governance and Social Entrepreneurship. Mexico: UNAM-ENTS

[4] Castiglioni, M., Castro, I. and Galan, JL (2015). The use and choice of alliances multipatner: an exploratory study. Market Economic \& Business Journal , 45 (1), 95-123 DOI: 10.7200 / esicm.150.0461.2e

[5] Contreras, G. (2012). Asociacionismo network for integration sociodigital in Andalucia . Andalusian Studies Journal, 29, 105-126 DOI: 10.12795 / rea.2012.i29.05

[6] Dominguez, G. Fuentes, J. (2006). Communication and information comoo generators competitiveness in organizations. Accounting and Management, 50, 207230

[7] Economist Intellig ence Unit (2010). Women's economy opportunity . London: EUI

[8] Economist Intelligence Unit (2015). Evaluating the environment for public-private partnerships in AsiaPacific . London: EUI

[9] Manktelow, A. (2014). Guide to Emerging Markets . London: Economist Intelligence Unit

[10] Martinez, A. (2012). Analysis of enterprise networks and territorial impact. Technology transfer, learning and innovation. Andalusian Studies Journal, 29, 18-58 DOI: 10.12795 / rea.2012.i29.02

[11] Pariente, JL (2006). Training administrators in the new international environment. Accounting and Management, 50, 124-144

[12]Ramos, L. (2013). Alliances and networks of collaboration ng between cultural groups of ethnic arts in Andalucia . Empriia , 15, 26-34 DOI: 10.5944 / empiria.26.7151

[13] Robles, C. , Alviter, LE, Ortega, AO and Martinez, E. (2016). Culture of quality and innovation in microenterprises. In M. Quintero., Sales, J. and Velazquez, EB (ed.). Innovation and technology. Challenges for practical application in companies. (pp. 11-27). Mexico: Porrúa-UAEMEX 